\title{
Resources Overview of solid waste
}

\author{
Xiaomei Zhou \\ School of North China Electric Power University,Baoding 071000,China \\ 1540169008@qq.com
}

Keywords: solid waste, resource, environment.

\begin{abstract}
Solid waste is harmful to human waste, but also for the development and utilization of secondary resources. This paper outlines the industrialization path of various solid waste and solid waste recovery using industry has great advantages in resources, solid waste resource technology were discussed.

Solid waste is referred to as the "misplaced resources" because of its high recovery value,if it is not disposed might cause many environmental problems, but also a waste of resources.Recycling of solid waste is the use of appropriate technical material and energy recovery from solid waste and create economic value.It can not only make the disposal of solid waste effectively,reduce the pressure on the environment, the space of the damage to the surrounding environment, can also reuse the useful resources of it.Solid waste resource is the concrete practice of the development of circular economy, the reality of our country determines the resource bound is an important measure and development direction of solid waste management in China.At present, the shortage of resources per capita global problems exposed gradually and become more and more serious, thus promoting recycling of solid waste is not only increasing the economic and social development needs, but also an important way to protect the environment and prevent pollution. The following are some of the ways of resource of solid waste.
\end{abstract}

\section{Utilization of municipal solid waste}

\subsection{Pretreatment of Municipal Solid Waste}

Put the mixed garbage collection into the pretreatment system, firstly separat bulky items, torn bags, spray deodorant and other processing, then use the drum sieve sorting after an artificial auxiliary sorting on the conveyor belt.The next to different garbage do corresponding processing and the organic material is fed into the anaerobic fermentation process.

, other groups divided into air and magnetic separation process, pick out plastic, paper, metal, rubble and some hazardous waste(such as lighters, batteries, etc.) .

\subsection{Recycling of Renewable Resources}

Obtained by the winnowing of the light components in the mainly for waste paper and plastic products, after being crushed, plastic products enter the plastic granulation machine, can be made into new products (such as plastic, etc.) to use again; direct recovery of paper products; ferromagnetic metals and nonferrous metals can be directly recovered after magnetic separation and artificial auxiliary separation; hazardous waste (such as batteries, etc.) is processed individually.

\subsection{Biomass Energy Pproduction}

This approach is mainly aimed at organic waste, which uses continuous dry anaerobic fermentation processing technology and conversion device, the organic waste is recycled as methane which is green clean biomass energy.In the process of high temperature can completely eliminate the harmful bacteria and other harmful substances.The process output of biogas can be used for power generation, in addition to meet the needs of the garbage treatment plant their own energy needs but also for, further upgrade for natural gas for automobile fuel gas or into the biogas pipe network. This process can get rid of the traditional process for the treatment of garbage brought the problem of the secondary pollution and low efficiency of environmental,it can realize the harmless treatment of garbage, energy utilization and ecological virtuous circle. 


\subsection{Combustible Material Resources}

Combustible matter is sorted out in the pretreatment of garbage,it produces biogas residue after anaerobic fermentation further after drying process as one of the raw materials into fuel production processes, and then broken up into the batching machine according to the proportion of ingredients, input shaping machine extrusion, made into new environmentally friendly fuel.The calorific value of new fuel even may surpass that of the ordinary coal-burning, it can be the substitution of ordinary coal-burning for universal fuel equipment, moreover its emission intensity is a lot lower compared to the ordinary coal-burning, may realize the standard emission.

According to the process, more than $90 \%$ of the urban living garbage can achieve resource recycling, the remaining small amount that can not be recovered can be disposed of in a landfill, hazardous waste has to be sent to professional agencies. This process digs potentials that solid waste recycles in energy utilization furthest, give full play to the strengths of various processing methods: on the one hand the waste once again has the value for people to use; on the other hand also does not produce secondary pollution, solve the most of the city garbage completely, bring great convenience for people's life.

\section{Utilization of Industrial Solid Waste}

There are many sources of industrial solid waste: metallurgical industry, mining industry, light industry, mechanical and electronic industry, construction industry and so on. This paper mainly introduces the recycling of electronic waste, construction waste and waste plastics.

\subsection{Resource Disposal of Electronic Waste}

Electrical and electronic equipment of various types, complex manufacturing processes,they contains a lot of metals, plastics, glasses and other compounds, including many toxic and harmful elements, such as chlorofluorocarbons, halogen flame retardants, mercury, selenium, nickel, cadmium, lead, chromium and so on. Therefore, treatment of electronic waste is different from general solid waste and its treatment of technology and technology requirements are very high, once the improper handling will cause great damage to the environment. On the other hand, a lot of useful elements in the electronic waste have a high recycling value and broad prospects . According to the research of the Technical University of Denmark showed that 1 t random collection of electronic board contains about plastics $271.8 \mathrm{~kg}$, copper $129.6 \mathrm{~kg}$,gold $0.5 \mathrm{~kg}$, iron $40.8 \mathrm{~kg}, \mathrm{~Pb}$ $29.4 \mathrm{~kg}$,nickel $19.9 \mathrm{~kg}$,tin $18.1 \mathrm{~kg}$,antimony $10.0 \mathrm{~kg}$. Electronic waste plastics and metals, especially rare metals have a very high value, its fully reuse, not only can solve the problem of environmental pollution effectively, but also can save a lot of resources, and create considerable economic benefits.

Process of recycling of electronic waste contains two meanings: (1) Reuse. Repair or upgrade the discarded electronic products to prolong their service life; (2) Recycling, recycl the materials including the dismantling of the components used. Through repairing or upgrading components to maximize the use of electronic waste, and there are almost no environmental pollution. The methods mainly include fire method, wet method, mechanical separation and biological recovery. The fire method and wet recovery will cause secondary pollution seriously to the environment, biological recovery method is still under development. The mechanical processing method of electronic waste includes electronic waste dismantling, crushing, sorting and other materials processing. The stage of electronic waste mainly use of the difference of magnetic ,electric properties and the density to separate. It's main advantage is that the pollution is tiny, and can be used for comprehensive recycling of electronic waste metal and non-metallic components. In recent years, with the use of the environment protection and electronic products of precious metals gradually reduced, mechanical recovery method waste gradually occupy the leading advantage in the research of electronic waste recycling.

\subsection{The recycling construction waste}

Clay brick and concrete have always been the most commonly used building artificial materials in our country, So the construction waste is mainly composed of waste concretes and bricks(followed by a small amount of broken ceramics, broken glasses, broken pieces of woods, mortars, slags, 
scrap metals, plastics, etc).After crushing and sorting construction waste can be obtained the desired particle sizes of recycled sand and stone,if using the proper processing technology, the reclaimed sand and stone can completely or partly replace natural building sand and stone, as one of the raw materials for the production of concrete wall products and recycled aggregate concrete, ready-mixed mortar.

2.2.1 Inorganic matters recycling. After treatment, the stones, concrete blocks and bricks in the construction waste can be used as the aggregate of concretes and mortars, which can be directly used for reinforcing soft soil foundation. The principle is to use the inorganic materials in construction waste forms to disperse the shape material spur pile, causes and pile between the steelyard weight impact the interaction, forms the compound ground, thus achieves to enhance the ground supporting capacity function. Waste bricks and mortars mixed with Portland cement adding auxiliary material, can produce lightweight blocks; After the configuration process, waste cements, bricks, stones, sands can be made into hollow bricks, solid bricks, etc. The products compared with clay brick, has many strengths such as the high compressive, abrasion resistance, low water imbibition, light, heat preservation, sound insulation.

2.2.2 Waste recycling. The metal such as scrap steel, steel wire, wire and all kinds of steel accessories, after sorting, concentration, re-melted can be manufactured into various specifications of steel; Except as a template and construction material recycling, waste wood and construction material can be used as raw material or as a raw material after the crusher by timber crushed into scrap; waste wood, sawdust, etc. can be used to manufacture a variety of man-made sheet; refining waste plastic can be reduced to an oil law, as a fuel, or processed into other renewable plastic products; broken glass can be processed into recycled glass or some decorative materials.

\subsection{The Recycling of Waste Plastics}

Waste plastics production is still growing rapidly, it is urgent to solve the environmental pollution problem caused by plastics. This is a large mistake in the process of development.

From the perspective of a permanent cure, treatment methods are:(1)Develop and product degradable plastics, such as light biodegradable film.(2)Replace plastic applications with other materials, such as paper snack box for plastic production.(3)The development of regulations to disable plastics, such as disabling the disposable bags.However, the above method has a number of shortcomings:The production of biodegradable plastic products, science and technology investment, high cost; substituted with other material will inevitably produce environmental problems; Disable bring inconvenience to the life. So these measures can't solve the problem of waste plastics processing very well.The measures being taken are: In order to facilitate recycling plastic after use, develop and product aging resistant plastic products (such as anti-aging plastic film); In order to reduce the amount of waste plastic, use reusable products.

According to the triumph of waste plastics recycling all around the world, waste plastics recycling route can be divided into the following types:

(1)Direct regeneration: sort recycled plastic first, then according to the different varieties crushing, melting, mixing, granulation, molding and other processing operations, to make plastic industrial raw material or plastic.

(2)Modification regeneration: generally sort recycling plastic, melt similar nature or mutually soluble plastic, add various additives for mixing, molding, to product all kinds of plastic products.

(3)Direct application: Make full use of the physical and chemical properties of plastic. Directly mix to other inorganic or organic material after crushing to made of industrial products, such as plastic concrete, foam concrete insulation board, etc.

(4)Auxiliary Applications: assisting application Plastic as auxiliary materials, mixed with a plastic raw materials or other materials, processed into all kinds of plastic products and plastic modified product, such as plastic ointment, waterproofing materials, coatings, adhesives, etc.

(5)Oil and gas fuel: product of gasoline, kerosene, diesel oil, methane gas and other chemical raw materials by high-temperature catalytic cracking recycled plastic. (6)Chemical analysis: mix recycled plastics and chemical reagent, reaction, cracking for small molecular monomers, chemical raw materials. 
(7)Solid fuel: after recycling plastic crushing or melt granulation, process into granular or powder and sold as a solid fuel.

(8)Direct production capacity: throw the recycling of waste plastics along with other combustible organic material into the incinerator to generate heat or electricity.

\section{Utilization of agricultural solid waste}

\subsection{Development and Utilization of Biological Feed}

The gradual rise of straw biological feed treatment technology changes from the initial physical trea tment to chemical treatment and biological treatment. further more, the present development of fer mentation technology engineering bacteria fermentation technology. The so-called engineering bact eria is the crop straw rubbing and adds microbial fermentation. It simulates the strains with cellulos e fungi medium to create specific fermentation environment to help it soften, after maturity transfor mation characteristics of biological feed engineering bacteria fermentation technology is easily pass nutrient regulation and improve the content of nutrients, so that biological feed strikes a

balance between the various nutrients and nutrient elements. After this techniqual treatment ,Not on ly the diet palatability is improved, but also the digestion rate is increased, which further increases $t$ he animal feed intake and production performance.

\subsection{Winter Livestock and Poultry Shed Biological Heat Pad Material.}

Pad material fermentation bed breeding technology is the application of agricultural by-products, such as Artemisia straw, blighted shell, leaves and grasses, sawdust, peat and so on ,they are compounded into a bio heat pad material according to a certain proportion . Make padding fill in animal bed and mixed with the outlet water and waste,then be fermented by the natural probiotics , which can both consume crops straw and absorb livestock manure, but also generated a lot of heat in the fermentation process, so as to improve the environment of the barn. Pad, the second year spring and then put the abandoned material in farmland as the organic fertilizer application, which not only can improve soil structure, but also can raise the productivity of the soil.

\subsection{Develop Cyclic Ecological Agriculture.}

The ignorance of livestock's faeces and corpse is not only a great waste of resources, but also cause serious pollution to the environment. Therefore, the use of organic waste of livestock breeding can not only reduce the environmental pollution which is caused by livestock and poultry production, but also can change into organic fertilizer for farmland after processing, which can improve the soil microbial ecological system and soil fertility to enhance the cultivated land productivity. The fundamental way to solve the problem of pollution is to realize the combination of planting and breeding, develop cyclic ecological agriculture, adopt the economy mode of "farming manure organic fertilizer - Organic farming - aquaculture". Construct ecological agriculture and control the recycling of phosphorus and nitrogen from the source to achieve the economic and ecological benefits of the "win-win", which is the focus of modern agriculture sustainable development.

\subsection{Promote the Mode of "Ecological Cultivation - Biogas - Green Cultivation"}

The adopt of the technology path of livestock's faeces - poultry manure methane fermentation pool - biogas, biogas residue, biogas slurry, which can apply biogas as a clean fuel to farmers. Using biogas slurry and biogas residue as organic fertilizer, not only can increase the yield of crops,but also can improve the quality of crop and resistance of pest and disease,which can achieve the effect of ecological circular economy demonstration garden in the family farm.Ultimately,this will promote the benign development of planting and breeding industry circular economy .

\section{Utilization of hazardous solid waste}

The hazardous waste is mainly from the nuclear industry, chemical industry, pharmaceutical industry, medical units and so on, hazardous waste treatment methods are incineration and landfill. But due to the technical limitations,we can not remove the risk of waste completely.

Co-processing in cement kiln is a very effective resource processing, because inside the kiln cement the temperature is high, under certain conditions, pollutants can be thoroughly burned, heavy 
metals can be fixed and no longer be discharged. In addition, disposal of hazardous waste can be alternative raw materials in the cement production process.

\section{Conclusion}

There are huge resource advantages in China's renewable resources recovery and utilization industry, and they contain the market immeasurable potential, but solid waste processing technology is lack of independent intellectual property rights of technology integration in our country, innovation ability is weak, research and development of solid waste still remain in learning and digesting other countries' advanced technology, lack of originality development. We should accelerate the solid waste industry science and technology innovation, enhance the technical level of the industry, combine with major environmental protection projects, support the development of environmental technologies with independent intellectual property rights. We need to increase investment, to create a diversified industrial investment environment, so as to realize the ultimate goal that turn the waste to treasures.

\section{References}

[1].Yifeng Sun,Yanyan Lin,Wenjuan Wang,Tianhua Xu,Tianyu Zhang,et al. The comprehensive utilization of solid waste.Technology \& Development of Chemical Industry.Vol.41(2012)No.1,p.46-47.

[2].Xiaopeng Wang,et al.Formation of agricultural solid waste and resource utilization. Animal Husbandry and Feed Science.Vol.36(2015)No.1,p.65-67.

[3].Xiangyang Tang,Guotao Gao,Guirong Zhu,et al. Resource Analysis and Countermeasure of MSW. China Environmental Protection Industry. Vol.41(2010)No.1,p.45-48.

[4].Peng Wang,et al. Pollution prevention and recycling of electronic waste. China Resources Comprehensive Utilization.Vol.9(2005)No.9,p.30-34. 